\title{
Study on the pattern of prescriptions available at rural households in Bangladesh
}

\author{
Md. Mahfuzar Rahman', Muzaherul Huq², Md. Atiqur Rahman
}

'Professor, ${ }^{3}$ Senior Lecturer, Department of Community Medicine, Anwer Khan Modern Medical College, Dhanmondi, Dhaka, Bangladesh. ${ }^{2}$ Regional Advisor (HRH), World Health Organization, Regional Office for South-East Asia, New Delhi, India.

\section{Abstract}

This was a descriptive type of cross-sectional study conducted in October, 2010, in three villages of Shahjadpur Upazila of Sirajganj district in Bangladesh. Among the rural households, those who visited medical practitioners in the last three months, were included in the study. The present study aimed to examine the pattern of prescriptions available at rural households of Bangladesh, to analyze the prescriptions whether diagnoses and/or lifestyles advice were mentioned, and to find out number of drugs and antibiotics (including their dose and duration of use) prescribed. During last three months, $68 \%$ respondents had attended a doctor's chamber; however, prescriptions were available for $57 \%$ of the respondents. More than three quarters of the prescriptions (77.6\%) included 3-5 medicines, and antibiotics were prescribed to 194 $(61 \%)$ respondents which constituted $21.4 \%$ of the total number of drugs prescribed. The average number of drugs and antibiotics prescribed per prescriptions was 3.8 and 1.3 respectively. Only about 23\% of the respondents received antibiotics for $3-6$ days, $30 \%$ for 2 days, and $46 \%$ for one day. Advice on lifestyles and diagnoses were mentioned only to $32 \%$ and $52 \%$ prescriptions respectively. The study also found that $22.6 \%$ of the prescriptions were made by unqualified doctors. Specific programs should be implemented to motivate and train medical students, practitioners and allied health professionals to provide rational prescriptions to the consumers in regards to the number of drugs as well as clarity of instructions given in the prescriptions.

Keywords: Pattern of prescription, Rational use of antibiotics, Advice on lifestyle, rural household, Bangladesh.

\section{Introduction}

Health is an important individual and community need. Both preventive and curative medicines take the help of drugs to fulfil their respective aims. Each of the drugs has certain effects which are not sought for but have to be accepted. In most instances, it apparently does not harm the patients but sometimes the results have negative health consequences. Overuse of medicine should be considered as an undesirable and money wasting practice. ${ }^{1}$ In 1975, World Health Organization (WHO) recommended to select and procure, at reasonable cost, the essential drugs of established quality according to the national health needs of the country. ${ }^{2}$ Subsequently, historic Alma-Ata declaration, which outlined the eight essential components of primary health care, incorporated provision of essential medicines is one of componenets.

Medicines are integral parts of modern healthcare services, not only save lives and promote health, but prevent epidemics and diseases. ${ }^{1}$ The medicines are undoubtedly one of the weapons of mankind to fight disease and illness. Access to medicines is the fundamental right of every person. Irrational

\section{Practice points}

- The present study identified the potential problems of polypharmacy in the prescriptions available at rural households in Bangladesh.

- More than three quarters of the prescriptions included 3-5 drugs and more than half the prescriptions included at least one antibiotic.

- Advice on lifestyles was mentioned in one-third and diagnoses were written in half of the prescriptions.

- A significant portion of prescriptions was prescribed by non-qualified doctors.

- Specific programs should be implemented to motivate and train medical students, practitioners and allied health professionals regarding safe and effective prescribing.

drug use and inappropriate prescribing by healthcare professionals is a worldwide trend, most notably prevalent in developing countries. ${ }^{4}$ The main causes include: lack of

Correspondence: Md. Mahfuzar Rahman, Professor, Department of Community Medicine, Anwer Khan Modern Medical College, Dhanmondi, Dhaka, Bangladesh.E-mail: mahfuzarrahman26@yahoo.com. 
continuing education and training and up-to-date knowledge of clinical pharmacology, inappropriate information from promotional materials of pharmaceutical companies, patient's pressure for medications of their choice, uncertainty about diagnosis, and direct stake of prescribers in selling more drugs. ${ }^{4,5}$ A study carried out in Japan showed that physicians tended to increase their income by prescribing more drugs than are needed for any particular disease. ${ }^{6}$ In Sri Lanka, Angunawela pointed out that drugs are sometimes prescribed without any specific indications and these are mostly mixtures, vitamins, and antimicrobials. ${ }^{7}$ In addition, prescriptions tend to increase the number of drugs prescribed per encounter and consequently leads to polypharmacy. Several factors and sources of drug information are also responsible for influencing physicians' prescribing pattern; among them are patient's demand, clinical experience, pressure from pharmaceutical companies and their representatives, house journals, drug samples, reference books, meeting, colleagues, and social cost and reward. ${ }^{8-10}$

Doctors bear the main responsibility for the use of drug. Several countries have adopted an essential drugs list but these had limited influence on the attitude and prescribing behaviour of the doctors. ${ }^{11}$ For example, a study in Denmark found that $61.7 \%$ of the prescriptions were incorrect and diagnoses were mentioned in only in $32.4 \%$ of the prescriptions. $^{12}$ An analysis of 600 prescriptions of private practitioners in Bangladesh found that drugs were prescribed in generic name only in 5 prescriptions, $50 \%$ drugs were prescribed from the Essential Drug List, and only $17.5 \%$ of prescriptions were complete in respect to patient medical information, and on average 3.81 drugs were prescribed per prescriptions and antibiotics were prescribed in $72.5 \%$ of the prescriptions. ${ }^{13}$ The present study aimed to examine the pattern of prescriptions available at rural households of Bangladesh, to examine the socio-demographic characteristics of the respondents, to analyze the prescriptions whether diagnoses and/or lifestyles advice were mentioned, and to find out number of drugs and antibiotics (including their dose and duration of use) prescribed.

\section{Methods}

This cross-sectional descriptive study was conducted in Saktipur, Parkola and Prannathpur villages of Shahjadpur Upazila in Bangladesh in the month of October, 2010. Among the rural households, those who had visited a medical practitioner within the last three months (from JulySeptember 2010) and were willing to respond were included in the study. The sampling technique was purposive. The sample size was 550 rural households. The data were collected face to face by trained interviewers through house visits with a pre-tested interview schedule and by collection of prescription details. The procedure also included a testing of $5 \%$ questionnaires of the total sample size in a place other than study area. Informed consent was sought from the participants and confidentiality of the information was maintained. All statistical analyses were performed using the Statistical Package for the Social Sciences (SPSS). Descriptive data has been given as frequencies and percentages.

\section{Result}

The socio-economic characteristics of the respondents are shown in Table 1. Respondents had a mean age of 34.8 years $(\mathrm{SD}=+13.09)$ and almost $73.3 \%$ respondents were found within age of 15-44 years of age. Approximately $73 \%$ respondents were found below SSC level of education, whereas $12.7 \%, 6 \%, 5.5 \%$ and $2.6 \%$ respondents had education equivalent to SSC, HSC, graduation, and postgraduation respectively.

Among 550 respondents, 375 (68\%) visited the doctors chamber during last three months (Table 2); however, availability of prescriptions was found only to $57 \%$ respondents as $11 \%$ prescriptions were found lost by the respondents.

The average number of drugs prescribed per prescriptions was 3.8. The range of drugs prescribed varied from 3 to 5 in about $77.6 \%$ of prescriptions (Fig. 1). There was not a single prescription wherein no drug was prescribed. Antibiotics were prescribed to 194 (61\%) respondents which constituted $21.4 \%$ of the total number of drugs prescribed (Fig. 2). The average number of antibiotics prescribed per prescriptions was 1.3. A single antibiotic was prescribed to 137 respondents, two antibiotics were prescribed to 49 respondents and three antibiotics were prescribed in the remaining 8 respondents. Only about $23 \%$ of the respondents received antibiotics for 3-6 days, 30\% for 2 days, and $46 \%$ for one day.

Table 1: Socio-economic characteristics of the respondents

\begin{tabular}{|l|c|}
\hline Socio-economic characteristics & $\begin{array}{c}\text { Number of } \\
\text { respondents }\end{array}$ \\
\hline Age in year & $155(28.2 \%)$ \\
\hline $15-24$ & $141(25.6 \%)$ \\
\hline $25-34$ & $107(19.5 \%)$ \\
\hline $35-44$ & $97(17.6 \%)$ \\
\hline $45-54$ & $50(9.1 \%)$ \\
\hline $55-64$ & $403(73.3 \%)$ \\
\hline Education & $70(12.7 \%)$ \\
\hline$<$ SSC (less than 10 years schooling) & $33(6 \%)$ \\
\hline SSC (10 years schooling) & $30(5.5 \%)$ \\
\hline HSC (12 years schooling) & $14(2.6 \%)$ \\
\hline $\begin{array}{l}\text { Graduation (14-16 years schooling) } \\
\text { Post Graduation (>14 or 16 years } \\
\text { schooling) }\end{array}$ & \\
\hline
\end{tabular}


Table 2: Attendance in the doctor's chamber and prescription particulars

\begin{tabular}{|l|c|}
\hline $\begin{array}{l}\text { Attendance and prescription } \\
\text { particulars }\end{array}$ & Numbers \\
\hline $\begin{array}{l}\text { Attending doctors' chamber during } \\
\text { last three months }\end{array}$ & $375(68.2 \%)$ \\
\hline Yes & $175(31.8 \%)$ \\
\hline No & \\
\hline Advices on lifestyles & $102(32.1 \%)$ \\
\hline Yes & $216(67.9 \%)$ \\
\hline $\begin{array}{l}\text { No } \\
\text { Diagnosis of diseases mentioned in } \\
\text { the prescription }\end{array}$ & $168(52.8 \%)$ \\
\hline Yes & $150(47.2 \%)$ \\
\hline No & $246(77.4 \%)$ \\
\hline Qualification of prescribed doctors & $72(22.6 \%)$ \\
\hline Qualified & \\
\hline Unqualified & \\
\hline
\end{tabular}

The recommended dosage of antibiotics was not mentioned in $29 \%$ of the prescriptions. Advices on lifestyle were found only in around one third of prescriptions (32\%) and diagnosis of disease was mentioned only in about $52 \%$ prescriptions. Among the available prescriptions, 22.6\% were from the non-qualified doctors.

\section{Discussion}

The present study was conducted to explore the pattern of prescriptions available at rural households in Bangladesh. The main findings revealed that more than three quarters of the prescriptions included three to five drugs and more than half the prescriptions included at least one antibiotic. The recommended dosage and duration of antibiotic usage were not mentioned in about one-third and three-fourth of the prescriptions respectively. Advice on lifestyles was

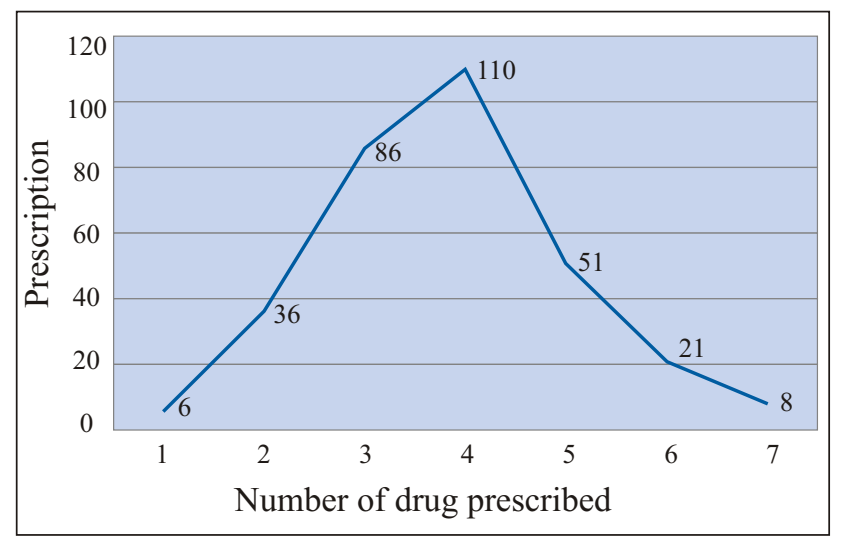

Figure 1: Distribution of number of drugs per prescription

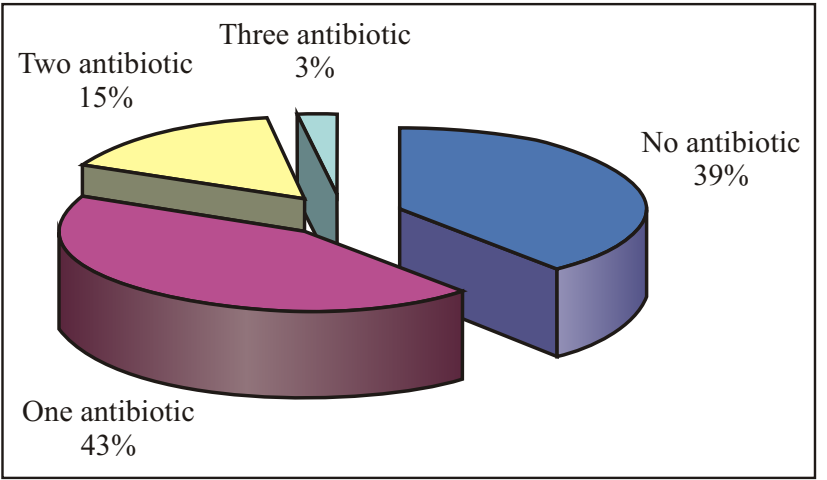

Figure 2: Distribution of number of antibiotics per prescription

mentioned in one-third, diagnoses were written in half of the prescriptions, and most importantly a significant portion of prescriptions was prescribed by non-qualified doctors.

We found average 3.8 drugs per prescription; however, a previous study from Bangladesh ${ }^{14}$ has reported a figure of 1.4 drugs per encounter. The figure of 3.8 drugs per encounter in the present study is higher than the recommended limit of 2.0 suggested by WHO. ${ }^{15}$ Our findings are similar to the findings reported in India, ${ }^{16}$ Cambodia, ${ }^{17}$ Nepal, ${ }^{18}$ Pakistan, ${ }^{19}$ Sri Lanka ${ }^{20}$ and Nigeria ${ }^{21}$ (2.2 to 4.8 drugs per encounter). Prescribing three or more drugs increases the risk of drug interactions, dispensing errors, and proper comprehension of the correct dosage and moreover, development of antibiotic resistance. ${ }^{16}$ Such irrationalities in prescribing medicines and limited advice given to patients indicate that traditional teaching in medical schools and continuing professional development do not equip students and physicians for rational therapeutics. ${ }^{14}$ This is probably because their pharmacology training has more emphasis on theory than on practical aspects of prescribing. ${ }^{13,22}$

Irrational use of antibiotic use remains the primary factor in the emergence and spread of antibiotic resistant organisms. Appropriate use of antibiotics is necessary to prevent emergence of drug resistant bacteria. Our figure of $61 \%$ prescriptions having an antibiotic which is much higher than the studies conducted in Bangladesh, ${ }^{14}$ India, ${ }^{16}$ Lebanon, $^{23}$ Nepal, $^{18}$ and Tanzania $^{24}(17.5 \%$ to $39.6 \%)$. In the present study, limited information was provided in the prescription regarding the duration of antibiotics and clinical diagnoses; one of the reasons may be the inclusion of $22.6 \%$ of the prescriptions from non-qualified practitioners. A study in USA revealed that $21 \%$ of all prescriptions contained at least one prescription writing error. ${ }^{10}$ The limited information on clinical diagnoses, course of drugs and others advices on lifestyle does not help to maintain a correct record towards better treatment. Moreover, incomplete information hinder patients' drugs taking compliance. ${ }^{17}$ 
WHO stressed that drugs are essential tools for health care and for the improvement of quality of life of the population and patients. ${ }^{2}$ WHO also identified a number of essential drugs for the developing countries that proved significant efficiencies in promoting basic health care and health status of the population. ${ }^{25}$ Bangladesh formulated its National Drug Policy in 1982 to ensure that common people can get the essential and necessary drugs easily and to ensure the quality and safety of these essential drugs. ${ }^{26}$ However, the provision of availability, affordability and the rational use of drugs have not achieved as expected in the national drug policy. The irrational use of drugs, such as over-prescribing, practice of polypharmacy, use of unnecessary expensive drugs, and overuse of antibiotics and injections were observed in many studies. ${ }^{14,27}$

Evidence shows that knowledge deficiency due to inadequate professional training and dependency on biased information perhaps contributed in irrational prescribing of drugs. ${ }^{13,28}$ Das \& Rahman ${ }^{28}$ demonstrated that prevalence of vitamin prescribing and contribution of vitamins in the cost of drugs prescribed in vitamin containing prescription were significantly $(\mathrm{p}<0.001)$ decreased after educational interventions at rural governmental hospitals, nongovernment organizations and private settings in Bangladesh. It is essential to equip medical graduates about principles of prescribing and therapeutics, how drugs work, and basic knowledge about commonly used drugs. ${ }^{29}$ An attempt has to be made to educate and train the medical students and tomorrow's doctors about the methods and skills required to evaluate the prescribing pattern, which in turn would improve the understanding and perception about rational prescribing.

\section{Conclusion}

The present study identified potential problems of polypharmacy, and overuse/misuse of drugs, especially antibiotics, and incomplete information in the prescriptions available at rural households in Bangladesh. The findings of the study demand a large-scale investigation on the pattern of prescriptions in rural Bangladesh. Specific programs should be implemented to motivate and train medical students, practitioners and allied health professionals regarding safe and effective prescribing. Strengthening the capacity of government institutes and regulatory bodies (e.g. the Directorate of Drug Administration) to oversee the quality and price of the drugs and implementation of the regulations are essential. In the long run, this will help to minimize drug resistance as well as economic loss of the country.

\section{References}

1. Vance MA, Millington MR. Principles of irrational drug therapy. Int J Health Serv 1986;16:355-62.

2. WHO. The selection of essential drug. Second report of a WHO Expert Committee. WHO Technical Report Series 641. Geneva: World Health Organization, 1979.
3. WHO. Alma Ata Declaration. World Health Form 1981;2:5-22.

4. Melrose D. Bitter pills, medicine and the third world poor. Oxford: Oxfam, 1982.

5. MOH\&FW. Report of the workshop on utilization of study findings related to Essential Drugs Project, Bangladesh. Dhaka: Ministry of Health and Family Welfare and Essential Drug Project, 1989.

6. Abe MA. Japan's clinic physicians and their behaviour. Soc Sci Med 1985;20:335-40.

7. Angunawela II, Tomson GB. Drug prescribing patterns: a study of four institutions in Sri Lanka. Int J Clin Pharmacol Ther Toxicol 1988;26:69-74.

8. Christenson DB, Wertheirmer AI. Sources of information and influence on new drugs prescribing among physicians in an HMO. Soc Sci Med 1979; 13:313-22.

9. Plumridge RJ. A review of factors influencing drug prescribing (Part II). Aust J Hosp Pharm 1983;13:44-8.

10. Krupka LR, Vener AM. Prescription, drug advertising: trends and implications. Soc Sci Med 1985;20:191-7.

11. Hartley BH. Prescription writing. BMJ 1981; 282:711.

12. Shaughnessy AF, Nickel RO. Prescription writing patterns and errors in a family medicine residency program. J Fam Pract 1989;29:290-5.

13. Rahman Z, Nazneen R, Begum M. Evaluation of prescribing pattern of the private practitioners by the undergraduate medical students. Bangladesh $J$ Pharmacol 2009;4:73-5.

14. Guyon AB, Barman A, Ahmed JU, Ahmed AU, Alam MS. A baseline survey on use of drugs at the primary health care level in Bangladesh. Bull World Health Organ 1994;72:265-71.

15. International Network for Rational Use of Drugs and World Health Organization. How to investigate drug use in health facilities: Selected drug use indicators. EDM Research Series No. 7 [WHO/DAP/93.1]. Geneva: World Health Organization, 1993.

16. Karande S, Sankhe P, Kulkarni M. Patterns of Prescription and Drug Dispensing. Indian J Pediatr 2005;72:117-21.

17. Chareonkul C, Khun VL, Boonshuyar C. Rational drug use in Cambodia: study of three pilot health centers in Kampong Thorn Province. Southeast Asian J Trop Med Public Health 2002;33:418-24.

18. Ravi Shankar P, Partha P, Nagesh S. Prescribing patterns in medical outpatients. Int $J$ Clin Pract 2002;56:549-51. 
19. Najmi MH, Hafiz RA, Khan I, Fazli FR. Prescribing practices: an overview of three teaching hospitals in Pakistan. J Pak Med Assoc 1998;48 :73-7.

20. Angunawela I. A study of prescribing in rural Sri Lanka. Ceylon Med J 1989; 34:125-9.

21. Chukwuani CM, Onifade M, Sumonu K. Survey of drug use practices and antibiotic prescribing pattern at a general hospital in Nigeria. Pharm World Sci 2002; 24:188-95.

22. de Vries TPGM, Henning RH, Hogerzeil HV, Fresle DA. Guide to good prescribing: A practical manual. WHO/ DAP/94.11. Geneva: World Health Organization, 1994.

23. Hamadeh GN, Dickerson LM, Saab BR, Major SC. Common prescriptions in ambulatory care in Lebanon. Ann Pharmacother 2001;35 636-40.

24. Massele AY, Nsimba SE, Rimoy G. Prescribing habits in church-owned primary health care facilities in Dar
Es Salaam and other Tanzanian coast regions. East Afr Med J 2001;78:510-4.

25. Mahler H. The meaning of 'Health for all by the year 2000'. World Health Forum 1981;2:5-22.

26. DGHS. Bangladesh Health Service Report 1985. Dhaka: Directorate General of Health Services, 1985.

27. Islam N. Bangladesh national drug policy: an example for the Third World? Trop Doct 1999;29:78-80.

28. Das AK, Rahman MS. Prescribing vitamins at primary health care level: Exploration of facts, factors and solution. Bangladesh J Pharmacol 2010;5:92-7.

29. Maxwell S, Walley T. Teaching safe and effective prescribing in UK medical schools: A core curriculum for tomorrow's doctors. $\mathrm{Br} J$ Clin Pharmacol 2003;55:496-503. 